Original Research Paper

\title{
Towards a Higher Learning Motivation among Malaysian Undergraduate Students - A Case Study of Motivation Change in Malaysian Undergraduate Students after the Global Study Program (GSP) in Japan
}

\author{
${ }^{1}$ Lim Way Soong, ${ }^{2}$ Leow Meng Chew, ${ }^{1}$ Lim Chot Hun, \\ ${ }^{3}$ Hiroki Igarashi, ${ }^{3}$ Ioannis Gaitanidis and ${ }^{3}$ Satoko Shao-Kobayashi \\ ${ }^{1}$ Faculty of Engineering and Technology, Multimedia University, Melaka, Malaysia \\ ${ }^{2}$ Faculty of Information Science and Technology, Multimedia University, Jalan Ayer Keroh Lama, Melaka, Malaysia \\ ${ }^{3}$ College of Liberal Arts and Sciences, Chiba University, Chiba, Japan
}

Article history

Received: 06-07-2016

Revised: 24-11-2016

Accepted: 31-07-2017

Corresponding Author:

Leow Meng Chew

Faculty of Information Science and Technology, Multimedia

University, Jalan Ayer Keroh

Lama, Melaka, Malaysia

Email: mcleow@mmu.edu.my

\begin{abstract}
This research paper outlines the Malaysian and Japanese undergraduate students' learning motivation, before and after joining a Global Study Program (GSP) held in Chiba University, Japan from 14 March-28 March 2016. A total of 15 Malaysian undergraduate students from Multimedia University, consisting of 2nd year to 4th year students, joined the GSP together with 15 Japanese 1st year to 4th year undergraduate students from Chiba University. The study focused on examining students' learning motivation in three experiment phases. The 1st phase of experiment consisted of conducting surveys on all students before the commencement of GSP. The 2 nd phase of experiment consisted of daily observational measurements toward students' motivation and performance. Lastly, the 3rd phase of experiment consisted of conducting the same surveys again on all students after the GSP. Note that the survey consisted of 29 questions covering value components, expectancy components, affective components and self-perceived learning components. The results of this study indicated that the learning motivation of Malaysian and Japanese undergraduate students had significantly improved after joining the GSP course.
\end{abstract}

Keywords: Learning Motivation, Malaysian Undergraduates Students, Global Study Program (GSP)

\section{Introduction}

Motivation is defined as the psychological driven force that stimulates an individual to achieving a certain goal or performing a certain task (Maferima and Ayelet, 2014). Motivation is important in terms of learning and how it affects conceptual understanding (Rachel and Holly, 2013). Learning motivation, on the other hand, can be defined as the psychological factors that affect individual's behavior towards their learning process (Kleinginna and Kleinginna, 1981). In Malaysia, studies and surveys on Malaysian students' motivation toward learning are always on-going. For instant, Habibah et al. (1995) had conducted a survey of 1050 university undergraduate students for achievement motivation measurement in terms of area of study, ethnic group, gender, year of study (consisted only 2 nd and 3rd years) and place of origin. Thang et al. (2011) studied the motivation of Malaysian secondary students toward learning English. On the other hand, Othman et al. (2009) and Salmiza (2014) studied Malaysian students' motivation toward learning science and physics, respectively. These studies unveiled the importance of motivation in stimulating Malaysian students in learning and also served as couching guidelines for Malaysian lecturers and educators in the course delivery planning.

As Malaysia's vision is to become a developed nation in year 2020, it is of great necessity to have talents in every sector. One way of acquiring these talents is to create interest in seeking knowledge on the young Malaysians so that in future they will become one. Hence the study of Malaysian students' learning motivation becomes crucial (Othman et al., 2009). Some important facts were discovered by past researches in 
examining Malaysian students' learning motivation. One of the important yet undesired facts was the imbalanced focus on the extrinsic goal orientations to the intrinsic goal orientations (Ainol and Isarji, 2009; Samsiah et al., 2009; Thang et al., 2011). It was observed that Malaysian students were more extrinsically goal oriented than intrinsically goal oriented in learning and studying. Such findings explain why Malaysian students focused more on external achievements in the learning process, such as higher grades and better recognitions (Ainol and Isarji, 2009; Samsiah et al., 2009; Thang et al., 2011). On the other hand, these findings also provide the justification for why Malaysian students, in general, emphasized on getting good grades while lacked of curiosity in pursuing knowledge. Note that such trend in learning process had negative impacts on the Malaysian students. Firstly, it had been concluded by researchers that individual who focused more on extrinsic goals had relatively low levels of happiness and well-being (Ryan et al., 1996; Schmuck et al., 2000). Secondly, several studies had revealed that Malaysian students tend to be passive and instruction-oriented throughout the learning process (Koo, 2003; Thang, 2009), which is correlated to the higher level of extrinsic goal orientations. Note that such trend had been a common phenomenon among Malaysian students since the last decade and this has been an issue awaiting to resolve (Ainol and Isarji, 2009; Thang et al., 2011).

Several suggestions were provided by researchers to increase the students' intrinsic motivation. For instant, Thang et al. (2011) suggested that the educators should take initiatives by helping the students to build up the self-learning trends. Similar suggestion was proposed by Siddhu (2009) to encourage educators to formulate strategies and training that help students strengthen the self-learning trends. Although these suggestions seem legit and reasonable, there are no statistical data to support the claims.

To explore the possibility of learning motivation improvement among Malaysia students, the authors present a study on the Multimedia University (MMU), Malaysia's undergraduate students' learning motivation before and after joining the Global Study Program (GSP) organized by Chiba University (Chiba-U), Japan from 14 March 2016 to 28 March 2016. Both MMU and Chiba-U undergraduate students' learning motivation were measured for comparative study. It is believed that the learning motivation of Malaysian undergraduate students will improve after joining the GSP.

\section{Global Study Program (GSP)}

The GSP is not a cultural exchange program, but a 2week collaborative learning course for undergraduate students from two different countries to work together through a series of lectures, workshops and fieldwork, to provide ideas for the betterment of a situation related a given topic. The GSP's key concept is collaboration and it emphasizes interdisciplinary, critical thinking and multicultural understanding. The course activities are coordinated to make collaborative learning among students from different countries happen. Participants from both universities are usually divided into mixed groups of five to six students and each group pursues to discuss, research and devise ideas related to the given topic by engaging in intensive workshops almost every day.

The course is in fact composed of three parts - the pre-course, main course and post-course education. The pre-course education is offered between six to eight times and provides learning opportunities for students to become familiar with the course topic as this course is offered to students from all disciplinary backgrounds. Before the main course starts, students take lectures to gain basic knowledge and multiple academic perspectives on the course topic over Skype and work on collaborative tasks by using a cloud drive and SNS, such as Google drive and Facebook. The main course lasts usually two weeks. After the main course is over, students from two universities meet again online a couple of times for post-course education. During these sessions, some experts are often invited to give feedback on students' final ideas to help them reflect on their works.

GSP had been successfully organized by Chiba University several times in the past and had collaborated with universities in different countries such as Finland, Greece, Vietnam and Malaysia. In this study, a group of 15 MMU undergraduate students together with another 15 Chiba-U undergraduate students chose to enroll in this GSP course hosted by Chiba University of Japan. These students were tasked with group projects that involved workshop discussions and brainstorming, field research involving interviews with the local Japanese to get feedback on selected topics, proposing solutions on the identified issues and presenting the findings.

\section{Research Methodology}

\section{The Learning Motivation Framework}

The learning motivation of the $15 \mathrm{MMU}$ undergraduate students from Malaysia and 15 Chiba-U undergraduate students from Japan was being measured before and after the main-course of the GSP, where the motivation was measured using an adapted Motivated Strategies for Learning Questionnaire (MSLQ) by Pintrich et al. (1991). The MSLQ was chosen due to its popularity and reliability in motivation measurements (Pintrich et al., 1991). The sampling method used in this study is stratified sampling with targeted respondents comprising all the undergraduate students joining the GSP. Fig. 1 depicts the proposed Learning Motivation Model. In this model, the learning motivation can be evaluated by three major motivation components, namely the Value component, the Expectancy component and the Affective component. 


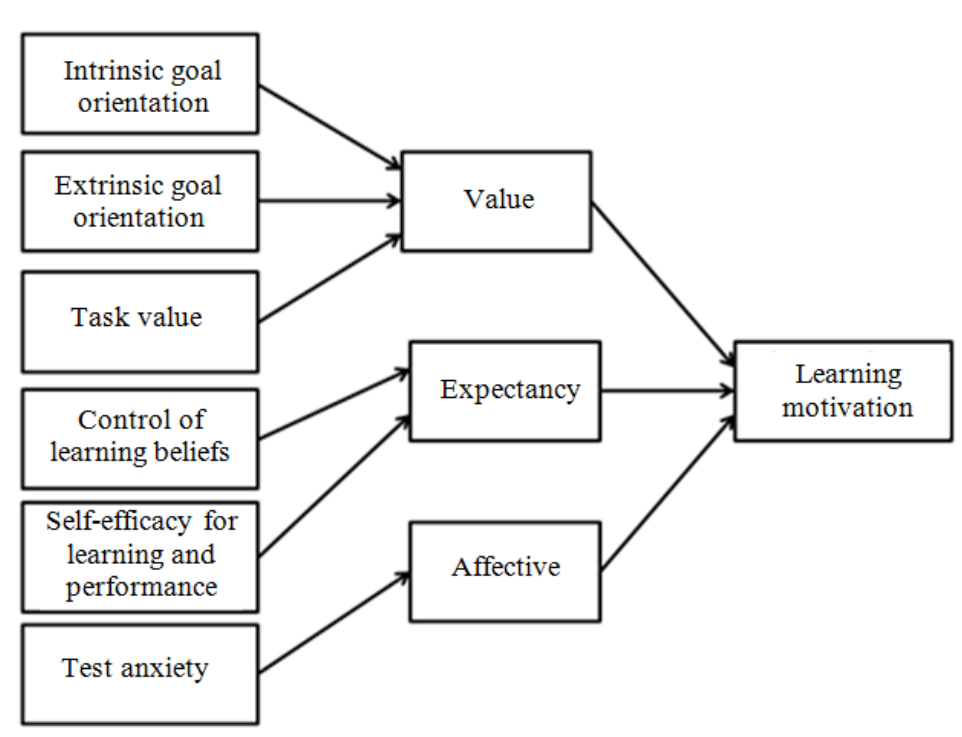

Fig. 1. The proposed learning motivation model

The Value component is sub-divided into Intrinsic Goal Orientation, Extrinsic Goal Orientation and Task Value, while the Expectancy component is sub-divided into Control of Learning Beliefs and Self-Efficacy components and the Affective component is tied directly to the Test Anxiety component:

- Value Component refers to elements that signified the individual's core value in learning motivation

- Intrinsic Goal Orientation refers to individual's internal motivations (such as curiosity and challenge) towards achieving a learning goal

- Extrinsic Goal Orientation refers to individual's external motivations (such as grades and rewards) towards achieving a learning goal

- Task Value refers to individual's perception (such as own interest and own importance) of the value of performing the learning task

- Expectancy Component refers to individual's positive expectation towards achieving a learning task

○ Control of Learning Beliefs refers to individual's beliefs towards how ones' effort is affecting the achievement of a learning task

- Self-Efficacy for Learning \& Performance refers to individual's judgments of own ability and performance expectation in performing a learning task

- Affective Component refers to individual's mental attributes that affect the learning task

$\circ \quad$ Test Anxiety refers to individual cognitive and emotionality components associated with the learning performance that has negative impact towards performing a learning task

\section{Materials and Methods}

This research measurement is carried out using the adapted MSLQ questionnaire (Pintrich et al., 1991). The survey questionnaire is shown in Table 1 . The questionnaire is set with 29 questions. The language used in the questionnaire is English. Note that the sequence of these 29 questions was arranged randomly (not according to the districts) in the actual questionnaire distributed to the students.

The subjects of study in this research were 15 undergraduate students from MMU, Malaysia and 15 undergraduate students from Chiba-U Japan. For MMU students, GSP is an elective program. Students who enrolled in this program were revealed through this study to be those who were active in university clubs and/or societies. For Chiba-U, GSP is a four-credit elective course opened for students from all levels to enroll. It was reported by Chiba-U International School Management that the GSP is perceived as a challenging elective course for undergraduates in Chiba-U. One of the challenges lie on the usage of English as the main reading and communicating medium throughout the course because the majority of the Japanese students perceive it as a difficult endeavor to communicate in fluent English (Ohata, 2005). Chiba-U students who enrolled in this course are deemed to be those who are willing to take up the challenge and wanting to have experience to work with students oversea collaboratively and enhance their English proficiency. In terms of demographic information, the MMU undergraduate students consisted of 2nd year to 4th year students with 9 males and 6 females, while the Chiba$\mathrm{U}$ undergraduate students consisted of $1 \mathrm{st}$ to 4 th year students with 11 males and 4 females. In addition, three Chiba-U students are foreign born. 
Table 1. The formulated questions for learning motivation measurements

Measurement districts
Value Intrinsic Goal Orientation (VI)

Questions

Value Intrinsic Goal Orientation (VI)

In this GSP program, I prefer course material that really challenges me so I can learn new things. (VII)

In this GSP program, I prefer course material that arouses my curiosity, even if it is difficult to learn. (VI2)

The most satisfying thing for me in this course is trying to understand the content as thoroughly as possible. (VI3)

When I have the opportunity in this GSP program, I choose assignments

Extrinsic Goal Orientation (VE) that I can learn from even if they don't guarantee a good performance (VI4) Getting a good performance in this GSP program is the most satisfying thing for me. (VE1)

The most important thing for me is improving my overall performance in this GSP program, so my main concern in the GSP program is getting a good performance. (VE2)

If I can, I want to get better performance in this GSP program than most of the other students. (VE3)

I want to do well in this GSP program because it is important to show my ability to my family and friends (VE4)

Task Value (VT)

It is important for me to learn the materials of this GSP program. (VTI)

I am very interested in the content area of this GSP program. (VT2)

I think the course material in this GSP program is useful for me to learn. (VT3)

I like the subject matter of this GSP program (VT4)

Expectancy Control of Learning Beliefs (EB) If I study in appropriate ways, then I will be able to learn the material in this GSP program $(E B l)$

It is my own fault if I don't learn the material in this GSP program. (EB2)

If I try hard enough, then I will understand the GSP course material. (EB3)

If I don't understand the GSP course material, it is because I didn't try hard enough (EB4)

Self-Efficacy for Learning and I'm certain I can understand the most difficult material presented in the readings for this GSP program $(E E l)$

Performance (EE)

I'm confident I can understand the basic concepts delivered in this GSP program (EE2)

I'm confident I can understand the most complex material presented by the instructor in this GSP program (EE3)

I'm certain I can master the skills being taught in this course (EE4)

Affective Test Anxiety (AA) When I take a test I think about how poorly I am doing compared with other students $(A A 1)$

When I take a test I think about items on other parts of the test I can't answer.(AA2)

When I take tests I think of the consequences of failing $(A A 3)$

Self Perception of Learning

I have an uneasy, upset feeling when I take an exam $(A A 4)$

Motivation (LM)

I feel excited to participate in the GSP program $(L M I)$

I have high expectation to learning new things in the GSP program (LM2)

I shall perform my best in the GSP program (LM3)

I anticipated fruitful learning experience in the GSP program. (LM4)

I am optimistic about having great experience in the GSP (LM5)

The overall experimental procedure is divided into three phases.

- In the first phase, the survey illustrated in Table 1 was administered to both MMU and Chiba-U undergraduate students. The results were collected and analyzed

- The second phase was carried out during the 2weeks GSP course, where students' behaviors towards the performance of the GSP course were observed and inferred to their motivation. The performance is examined from the perspective of persistence, accuracy and completion of milestones (Bargh et al., 2001; Maferima and Ayelet, 2014)
- In the third phase (upon the end of the program), the same survey was administered again to both MMU and Chiba-U undergraduate students. The results were being recorded and subsequently analyzed

In the second phase of the experiment, both Malaysian and Japanese students were involved in a series of workshops, field works, discussions and presentation. Students worked in groups that consist of both Malaysian and Japanese. The theme for the GSP this year was related to Japan's life space and healthcare technology. Throughout the program, students were tasked to discover and observe the problems that the 
elderly may be facing in two types of living environments: Elderly care home and a 40-year old housing estate complex. The students were expected to follow a schedule of $9.00 \mathrm{am}$ to $4.00 \mathrm{pm}$ daily as part of the GSP learning plan. The daily activities included workshops, field works, discussion sessions and presentation sessions.

Workshops: Several technical and non-technical workshops were organized for students to stimulate ideas to formulate solutions to the problems. These workshops were given by professional personnel who are experts in their respective fields. For example, Professor $\mathrm{Yu}$ from Chiba University had delivered a technical workshop related to engineering in robotics and how these technologies could possibly be implemented to solve the problems. Meanwhile Dr. Gaitanidis from Chiba University had delivered a non-technical workshop related to human factor and how these factor should be taken into consideration by students while formulating the solutions toward the problems.

Fieldworks: Several field works were co-organized by authors from Chiba University and the local institutions in Japan to allow students to examine the problems. For example, all students visited the Danchi (low cost apartment built by Japan Government) and a nursing home for elderly people as their fieldwork sites. During these visits, students interviewed the representatives from the local institutes with questionnaires formulated during workshops and discussions. Beside interviews, students were also being tasked to observe and to discover issues during the fieldworks.

Discussions: Various discussions were held among groups of students in order to work out suitable solutions for the problems from field works. These discussions were carried out on an open-ended basis. In these discussions, the students were divided into six groups, each consisting of a mixture of Malaysian and Japanese students.

Presentation: Students presented their proposed solutions to the local facility managers who will directly or indirectly benefits from the solutions.

The student's motivation was assessed based on observation on three specific aspects, namely the persistence towards the GSP, the completion of milestone and the accuracy of the work done (Bargh et al., 2001; Maferima and Ayelet, 2014). Observations were done on daily basis, except for the rest days and special activity day (cultural presentation day).

The persistence is evaluated based on student's level of perseverance in the program activities. It is measured based on how much time the student was participating in the program daily proactively. The expected activity duration was from $9.00 \mathrm{am}$ to $4.00 \mathrm{pm}$ daily. The observations were placed into three categories, i.e. less than expected duration, meet the expected duration and exceed the expected duration.

The completion of milestone was measured based on student's daily progress in the program. Students were to collaboratively complete certain tasks each day as part of the program objectives (the milestones). The observations of completion of milestone were divided into two categories, i.e. achieve and not achieve.

The accuracy of work done was evaluated based on how precise the students were in achieving the program objectives as a team. The evaluation focused on how well the students collaborated within the same team in completing the project. The observations of the accuracy of work done were placed into three categories, i.e., not accurately achieve, meet the expectation and exceed the expectation.

\section{Results}

The results collected from this study are separated into three different sections according to the three phases described in the methodology, namely the survey results obtained before the commencement of the GSP course, the observation results obtained from students' performance during the 2-weeks GSP course and the survey results obtained after the completion of the GSP course.

\section{1st Phase: Pre-Course Survey}

Before the commenced of the GSP course in Chiba$\mathrm{U}$, a pre-course survey was carried out on both MMU and Chiba-U participants. The survey was formulated based on the questionnaires as listed in Table 1. The general statistics of the pre-course survey were outlined in Table 2, in which Table 2 compared the means and standard deviations between the scores for students from the two universities based on individual construct. Note that the individual construct's acronym in Table 2 is well illustrated and shown in Table 1.

The survey results show that on average, MMU students had higher means in almost all constructs as compared to Chiba- $\mathrm{U}$ students. By solely judging from this pre-course survey, it may seem that MMU students are more motivated than Chiba-U students to participate in the GSP course. To justify the validity of these results, the Levene's Test and independent samples t-test were used. Note that running the Levene's Test on data in Table 2 revealed that only EE2 failed the Test. Hence, the statistical results from Table 2 will be put on t-test, except for EE2 where Mann-Whitney Test will be used to validate the differences.

Table 3 illustrates the t-test results of the constructs that pass the Levene's Test. Similar to Table 2, each individual construct of Table 3 is well defined in Table 1. Majority of the constructs show that the $95 \%$ Confidence Interval (CI) for mean difference contains the tested value 0 and the p-value of more than 0.05 , respectively. Hence there is no difference for these constructs in means for each score between MMU and Chiba-U students. However, there are 5 constructs with p-values computed to be less than 0.05 , namely the VT3, VT4, LM2, LM3 and LM5: 
Lim Way Soong et al. / American Journal of Applied Sciences 2017, 14 (8): 808.822 DOI: $10.3844 /$ ajassp.2017.808.822

Table 2. The general statistics of the pre-course survey

\begin{tabular}{|c|c|c|c|c|c|c|}
\hline \multirow[b]{2}{*}{ Individual constructs } & \multicolumn{3}{|c|}{ Multimedia University (Malaysia) } & \multicolumn{3}{|c|}{ Chiba University (Japan) } \\
\hline & Mean & Std. dev. & Std. err. mean & Mean & Std. dev. & Std. err. mean \\
\hline VII & 7.33 & 1.95 & 0.50 & 7.43 & 1.50 & 0.40 \\
\hline$V I 2$ & 8.60 & 1.45 & 0.38 & 7.93 & 1.82 & 0.49 \\
\hline$V I 3$ & 7.73 & 1.67 & 0.43 & 6.79 & 1.67 & 0.45 \\
\hline VI4 & 7.33 & 2.29 & 0.59 & 7.07 & 1.77 & 0.47 \\
\hline$V E 1$ & 6.4 & 1.76 & 0.46 & 7.36 & 1.78 & 0.48 \\
\hline$V E 2$ & 7.07 & 1.49 & 0.38 & 7.14 & 1.66 & 0.44 \\
\hline VE3 & 6.67 & 2.66 & 0.69 & 7.21 & 1.93 & 0.52 \\
\hline VE4 & 6.87 & 1.60 & 0.41 & 6.64 & 2.65 & 0.71 \\
\hline$V T 1$ & 7.80 & 1.90 & 0.49 & 7.07 & 1.86 & 0.50 \\
\hline$V T 2$ & 7.47 & 1.81 & 0.47 & 6.64 & 2.17 & 0.58 \\
\hline VT3 & 7.93 & 1.49 & 0.38 & 6.64 & 1.74 & 0.46 \\
\hline VT4 & 7.60 & 1.64 & 0.42 & 5.79 & 2.01 & 0.54 \\
\hline$E B 1$ & 7.93 & 1.58 & 0.41 & 7.43 & 1.40 & 0.37 \\
\hline$E B 2$ & 7.13 & 1.81 & 0.47 & 6.86 & 2.07 & 0.55 \\
\hline EB3 & 8.13 & 1.36 & 0.35 & 7.86 & 1.56 & 0.42 \\
\hline EB4 & 6.20 & 2.43 & 0.63 & 5.86 & 2.21 & 0.59 \\
\hline EE1 & 7.13 & 1.41 & 0.36 & 6.29 & 1.73 & 0.46 \\
\hline$E E 2$ & 8.2 & 0.86 & 0.22 & 6.64 & 1.55 & 0.41 \\
\hline EE3 & 7.27 & 1.53 & 0.40 & 6.36 & 1.39 & 0.37 \\
\hline EE4 & 7.27 & 1.83 & 0.47 & 6.36 & 1.95 & 0.52 \\
\hline$A A 1$ & 4.20 & 2.76 & 0.71 & 5.79 & 2.26 & 0.60 \\
\hline$A A 2$ & 6.33 & 2.23 & 0.57 & 6.14 & 1.51 & 0.40 \\
\hline$A A 3$ & 5.13 & 2.53 & 0.65 & 6.43 & 2.59 & 0.69 \\
\hline$A A 4$ & 5.73 & 2.84 & 0.73 & 7.64 & 2.24 & 0.60 \\
\hline LMI & 9.33 & 0.9 & 0.23 & 8.50 & 1.45 & 0.39 \\
\hline LM2 & 8.20 & 1.61 & 0.42 & 6.86 & 1.61 & 0.43 \\
\hline$L M 3$ & 8.80 & 1.57 & 0.40 & 7.29 & 2.13 & 0.57 \\
\hline LM4 & 8.20 & 1.52 & 0.39 & 7.14 & 1.41 & 0.38 \\
\hline LM5 & 9.27 & 1.16 & 0.30 & 7.21 & 1.97 & 0.53 \\
\hline
\end{tabular}

Table 3. Independent sample $t$-test results of the pre-course survey

\begin{tabular}{|c|c|c|c|c|c|c|c|}
\hline & \multirow[b]{2}{*}{$t$} & \multirow[b]{2}{*}{$\mathrm{df}$} & \multirow[b]{2}{*}{$p$-value } & \multirow[b]{2}{*}{ Mean difference } & \multirow[b]{2}{*}{ Std. error difference } & \multicolumn{2}{|c|}{$95 \%$ Confidence interval of the difference } \\
\hline & & & & & & Lower & Upper \\
\hline VII & -0.15 & 27 & 0.885 & -0.10 & 0.65 & -1.43 & 1.24 \\
\hline VI2 & 1.10 & 27 & 0.28 & 0.67 & 0.61 & -0.58 & 1.92 \\
\hline$V I 3$ & 1.53 & 27 & 0.138 & 0.95 & 0.62 & -0.33 & 2.22 \\
\hline VI4 & 0.34 & 27 & 0.735 & 0.26 & 0.76 & -1.31 & 1.83 \\
\hline$V E 1$ & -1.45 & 27 & 0.158 & -0.96 & 0.66 & -2.31 & 0.39 \\
\hline VE2 & -0.13 & 27 & 0.897 & -0.08 & 0.58 & -1.27 & 1.12 \\
\hline VE3 & -0.63 & 27 & 0.534 & -0.55 & 0.87 & -2.33 & 1.24 \\
\hline VE4 & 0.28 & 27 & 0.783 & 0.22 & 0.81 & -1.43 & 1.88 \\
\hline$V T 1$ & 1.04 & 27 & 0.305 & 0.73 & 0.70 & -0.70 & 2.16 \\
\hline$V T 2$ & 1.11 & 27 & 0.275 & 0.82 & 0.74 & -0.69 & 2.34 \\
\hline$V T 3$ & 2.15 & 27 & 0.040 & 1.29 & 0.60 & 0.06 & 2.52 \\
\hline VT4 & 2.68 & 27 & 0.013 & 1.81 & 0.68 & 0.42 & 3.21 \\
\hline EBI & 0.91 & 27 & 0.372 & 0.51 & 0.56 & -0.64 & 1.65 \\
\hline$E B 2$ & 0.38 & 27 & 0.704 & 0.28 & 0.72 & -1.20 & 1.75 \\
\hline EB3 & 0.51 & 27 & 0.615 & 0.28 & 0.54 & -0.84 & 1.39 \\
\hline EB4 & 0.40 & 27 & 0.695 & 0.34 & 0.86 & -1.43 & 2.12 \\
\hline EE1 & 1.45 & 27 & 0.158 & 0.85 & 0.58 & -0.35 & 2.05 \\
\hline EE3 & 1.67 & 27 & 0.107 & 0.91 & 0.55 & -0.21 & 2.03 \\
\hline EE4 & 1.30 & 27 & 0.206 & 0.91 & 0.70 & -0.53 & 2.35 \\
\hline$A A 1$ & -1.69 & 27 & 0.103 & -1.59 & 0.94 & -3.51 & 0.34 \\
\hline$A A 2$ & 0.27 & 27 & 0.791 & 0.19 & 0.71 & -1.27 & 1.65 \\
\hline$A A 3$ & -1.36 & 27 & 0.185 & -1.30 & 0.95 & -3.25 & 0.66 \\
\hline$A A 4$ & -2.00 & 27 & 0.056 & -1.91 & 0.96 & -3.87 & 0.05 \\
\hline LMI & 1.87 & 27 & 0.072 & 0.83 & 0.45 & -0.08 & 1.75 \\
\hline LM2 & 2.24 & 27 & 0.033 & 1.34 & 0.60 & 0.11 & 2.57 \\
\hline$L M 3$ & 2.19 & 27 & 0.037 & 1.51 & 0.69 & 0.10 & 2.93 \\
\hline LM4 & 1.94 & 27 & 0.063 & 1.05 & 0.55 & -0.06 & 2.18 \\
\hline LM5 & 3.45 & 27 & 0.002 & 2.05 & 0.60 & 0.83 & 3.27 \\
\hline
\end{tabular}


- For VT3, the sample mean for MMU students is $7.93 \pm 1.49$ while sample mean for Chiba-U students is $6.64 \pm 1.74$. The $95 \%$ CI for mean difference is $[0.06,2.52]$, which does not contain 0 . Thus, there is a difference in mean scores between MMU and Chiba-U students, in which the scores of MMU students are higher than Chiba-U students

- For VT4, the sample mean for MMU students is $7.6 \pm 1.64$, while sample mean for Chiba-U students is $5.79 \pm 2.01$. The $95 \%$ CI for mean difference is $[0.42,3.21]$, which does not contain 0 . Thus, there is a difference in mean scores between MMU and Chiba- $U$ students, in which the scores of MMU students are higher than Chiba-U students

- For LM2, the sample mean for MMU students is $8.2 \pm 1.61$, while sample mean for Chiba-U students is $6.86 \pm 1.61$. The $95 \%$ CI for mean difference is $[0.11,2.57]$, which does not contain 0 . Thus, there is a difference in mean scores between MMU and Chiba-U students, in which the scores of MMU students are higher than Chiba-U students

- For LM3, the sample mean for MMU students is $8.8 \pm 1.57$, while sample mean for Chiba-U students is $7.29 \pm 2.13$. The $95 \% \mathrm{CI}$ for mean difference is $[0.1,2.93]$, which does not contain 0 . Thus, there is a difference in mean scores between MMU and Chiba-U students, in which the scores of MMU students are higher than Chiba-U students.

- For LM5, the sample mean for MMU students is $9.27 \pm 1.16$, while sample mean for Chiba-U students is $7.21 \pm 1.97$. The $95 \% \mathrm{CI}$ for mean difference is $[0.83,3.27]$, which does not contain 0 . Thus, there is a difference in mean scores between MMU and Chiba-U students, in which the scores of MMU students are higher than Chiba-U students

For the construct EE2, the Mann-Whitney Test showed a mean rank score of 19.3 for MMU students and 10.39 for Chiba-U students. The Mann-Whitney U Test returns $p$-value of 0.003 . Since this value is less than 0.05 , hence there is a difference in the EE2 scores where MMU students scored higher in this instance.

\section{2nd Phase: The Observation Results}

Table 4 illustrated the students' performance based on the observations on the three aspects explained, while Table 5 described the daily observation on students' activities in this program. It could be observed from Table 4 and Table 5 that almost all students achieved the daily objectives in this program. Students in general were highly motivated throughout the program. The authors observed that students were putting efforts to complete the given task daily, even though there were language barrier among members in several groups.

In response to the single question "Why are you putting an effort in this GSP course?". For MMU students, the responses were:

- I am representing Malaysia and my university in this program. So I must do well in this program

- My Japanese group members are working hard in this program. I shall not be a liability to them

- The scholarship provided by the Japan government is a recognition towards my ability. Hence I must put extra efforts to accomplish the assigned tasks

For Chiba-U students, the responses were:

- The GSP course is one of the most challenging elective courses offered in Chiba University. I want to take up the challenge

- The GSP course allowed me to interact with foreign students using English, which is considered a rare opportunity in Japan

Table 4. Results of observational measurement

\begin{tabular}{|c|c|c|c|c|c|c|c|c|}
\hline Date & $\begin{array}{l}\text { Less than } \\
\text { expected duration }\end{array}$ & $\begin{array}{l}\text { Meet the } \\
\text { expected duration }\end{array}$ & $\begin{array}{l}\text { Exceed } \\
\text { expected duration }\end{array}$ & $\begin{array}{l}\text { Not } \\
\text { achieve }\end{array}$ & Achieve & $\begin{array}{l}\text { Not } \\
\text { accurately achieve }\end{array}$ & $\begin{array}{l}\text { Meet the } \\
\text { expectation }\end{array}$ & $\begin{array}{l}\text { Exceed the } \\
\text { expectation }\end{array}$ \\
\hline 15-Mar-16 & 0 & 0 & 30 & 0 & 30 & 0 & 30 & 0 \\
\hline 16-Mar-16 & 0 & 0 & 30 & 0 & 30 & 0 & 30 & 0 \\
\hline 17-Mar-16 & 0 & 0 & 30 & 0 & 30 & 0 & 30 & 0 \\
\hline 18-Mar-16 & 0 & 30 & 0 & 0 & 30 & 0 & 30 & 0 \\
\hline 19-Mar-16 & 0 & 0 & 30 & 0 & 30 & 0 & 30 & 0 \\
\hline 20-Mar-16 & 0 & 30 & 0 & 0 & 30 & 0 & 30 & 0 \\
\hline 21-Mar-16 & Rest day & & & & & & & \\
\hline 22-Mar-16 & 0 & 30 & 0 & 0 & 30 & 0 & 30 & 0 \\
\hline 23-Mar-16 & 0 & 30 & 0 & 0 & 30 & 0 & 30 & 0 \\
\hline 24-Mar-16 & 4 & 26 & 0 & 10 & 20 & 10 & 15 & 5 \\
\hline 25-Mar-16 & 1 & 29 & 0 & 1 & 29 & 0 & 25 & 5 \\
\hline 26-Mar-16 & 0 & 30 & 0 & 0 & 30 & 0 & 15 & 15 \\
\hline 27-Mar-16 & NA & & & & & & & \\
\hline
\end{tabular}


Table 5. Remarks on the observational measurement results

Date Remarks

15-Mar-16 free day Today was supposed to be a free day. However, all students stayed at Chiba University for cultural presentation preparation. It was observed that all students were highly motivated in completing their cultural presentation slides despite the fact that it was a free day for them. All students completed the presentation preparation in the end

16-Mar-16 field trips All students involved in two field trips to gain knowledge related to the GSP course. At the end of the field trips $(5.00 \mathrm{pm})$, students were tasked with the milestone to write a one page report to be submitted on the next day. All students took initiative to continue discussion to produce the report together. Majority of the students completed the report by 7.00pm. (All students submitted their reports on the next day)

17-Mar-16 technical field trips In the morning, all students involved in three technical field trips to gain knowledge related to the GSP course. Good responses were observed from students in raising critical questions on the projects they visited. After that, students worked extra time on brainstorming ideas and discussion. In the afternoon, all students involved in the cultural presentations

18-Mar-16 field trip From this day onward, students were divided into six groups where each group consisted of mixture of Malaysian and Japanese students. All students involved in field trip to gain insight on the living space in Chiba, Japan. Each group of students was tasked with the milestone to discover problems from the field trips through observations and by interviewing the locals. All students successfully listed several problems from their observations and interviews

19-Mar-16 workshop All students were involved in a half day workshop to propose ideas to solve the problems observed and field trip on 18-Mar-16. Each group of students proposed several ideas during the workshop. In the afternoon, students travelled back to yesterday's field trip location to interview the locals to check if their ideas can be accepted. After the field trip (4.00pm), students stayed back until late night to discuss on their findings from the field trip

20-Mar-16 discussions $\quad$ All students discussed their findings from the field trip on 19-Mar-16. Students were tasked to hold discussions among members of each respective group to identify the suitable ideas in solving the observed living space issue based on the feedbacks from the locals. Each group was able to determine several suitable ideas from their discussions by $4.00 \mathrm{pm}$

21-Mar-16 Rest day 22-Mar-16 workshop and field trip This was a rest day. Students were free from workshops and discussions

Each group of students was involved in a half-day workshop on forming survey questionnaires related to their ideas in solving the living space issue. In the afternoon, students travelled back to the field trip location to conduct the survey on the locals. Feedbacks from the locals were recorded.

23-Mar-16 presentation, discussion and field trip In the morning, each group of students presented their ideas in front of all students, and discussed the implications of the feedbacks from locals toward their ideas. Majority of the students were optimistic of their ideas, but were demotivated by the negative feedbacks from the locals. After the presentations, all group of students refined their ideas and the survey questionnaires. In the afternoon, students travelled back to the field trip location to conduct the last round of survey on the locals. Feedbacks from the locals were recorded

24-Mar-16 discussions In the morning, all groups of students discussed on the feedbacks obtained from the survey, and reflected on the outcomes of the surveys and ideas. In the afternoon, students finalized their findings, and started to prepare the 1 st draft of the final presentation. 4 students did not meet the expected hours due to sickness. 10 students (two groups) did not complete the 1 st draft of the final presentation slides due to the changing of ideas because of the local feedbacks, while 5 students (one group) showed good performance in terms of articulating ideas and producing new invention. Students continued with the final presentation slides preparation with guided instructions and discussions. 1 student did not meet the expected hours and performance due to sickness. 5 students (one group) showed good performance in terms of articulating ideas and producing new invention In the morning, all group of students finalized their presentation slides. In the afternoon, students presented their ideas and inventions to the audiences from related institutes. 15 students (3 groups) showed good performance in terms of articulating ideas and producing new inventions. Audiences from related institutes showed their interest on the invention, and were looking forward to see the implementation of these inventions

26-Mar-16 discussions and final presentation

27-Mar-16 closing ceremony Closing ceremony. End of program

\section{3rd Phase: Post-Course Survey}

A post-course survey was carried out after the end of the GSP on both MMU and Chiba-U participants. The survey was formulated based on the same questionnaires as listed in Table 1. The general statistics of the post-course survey were computed and outlined in Table 6 , in which Table 6 showed the means and standard deviations between the scores for students from the two universities based on individual construct. Note that each individual construct in Table 6 is well defined in Table 1. 
Lim Way Soong et al. / American Journal of Applied Sciences 2017, 14 (8): 808.822 DOI: $10.3844 /$ ajassp.2017.808.822

Table 6 . The general statistics of the post-course survey

\begin{tabular}{|c|c|c|c|c|c|c|}
\hline \multirow[b]{2}{*}{ Individual constructs } & \multicolumn{3}{|c|}{ Multimedia University (Malaysia) } & \multicolumn{3}{|c|}{ Chiba University (Japan) } \\
\hline & Mean & Std. Dev. & Std. Err. Mean & Mean & Std. Dev. & Std. Err. Mean \\
\hline VII & 7.53 & 2.446 & 0.631 & 7.73 & 1.387 & 0.358 \\
\hline VI2 & 9.20 & 0.862 & 0.223 & 7.80 & 1.781 & 0.460 \\
\hline VI3 & 7.47 & 2.264 & 0.584 & 7.60 & 1.805 & 0.466 \\
\hline VI4 & 8.13 & 1.807 & 0.467 & 7.20 & 1.373 & 0.355 \\
\hline$V E 1$ & 8.27 & 1.668 & 0.431 & 8.27 & 1.907 & 0.492 \\
\hline$V E 2$ & 8.33 & 2.289 & 0.591 & 8.33 & 1.633 & 0.422 \\
\hline$V E 3$ & 7.73 & 2.520 & 0.651 & 8.73 & 1.335 & 0.345 \\
\hline VE4 & 6.60 & 2.874 & 0.742 & 7.80 & 4.902 & 1.266 \\
\hline VT1 & 8.07 & 1.751 & 0.452 & 8.00 & 2.000 & 0.516 \\
\hline VT2 & 7.80 & 1.897 & 0.490 & 7.13 & 2.642 & 0.682 \\
\hline VT3 & 8.20 & 1.568 & 0.405 & 7.80 & 2.210 & 0.571 \\
\hline VT4 & 7.87 & 1.807 & 0.467 & 7.53 & 2.200 & 0.568 \\
\hline$E B I$ & 8.67 & 1.234 & 0.319 & 7.60 & 1.844 & 0.476 \\
\hline$E B 2$ & 7.40 & 2.384 & 0.616 & 6.87 & 2.100 & 0.542 \\
\hline EB3 & 8.53 & 1.407 & 0.363 & 8.27 & 1.223 & 0.316 \\
\hline EB4 & 7.53 & 2.696 & 0.696 & 7.13 & 2.356 & 0.608 \\
\hline EE1 & 7.20 & 1.935 & 0.500 & 7.20 & 1.373 & 0.355 \\
\hline$E E 2$ & 8.73 & 1.223 & 0.316 & 7.40 & 2.098 & 0.542 \\
\hline EE3 & 8.33 & 1.291 & 0.333 & 7.13 & 1.685 & 0.435 \\
\hline EE4 & 8.27 & 1.335 & 0.345 & 7.40 & 1.549 & 0.400 \\
\hline$A A 1$ & 5.00 & 3.381 & 0.873 & 6.07 & 1.907 & 0.492 \\
\hline$A A 2$ & 6.87 & 2.031 & 0.524 & 6.00 & 1.648 & 0.425 \\
\hline$A A 3$ & 5.87 & 3.335 & 0.861 & 5.67 & 2.664 & 0.688 \\
\hline$A A 4$ & 4.27 & 2.815 & 0.727 & 6.73 & 2.865 & 0.740 \\
\hline LMI & 9.47 & 0.915 & 0.236 & 9.20 & 1.146 & 0.296 \\
\hline$L M 2$ & 8.13 & 2.295 & 0.593 & 8.00 & 1.512 & 0.390 \\
\hline LM3 & 8.87 & 2.066 & 0.533 & 8.00 & 1.604 & 0.414 \\
\hline LM4 & 8.20 & 2.455 & 0.634 & 8.13 & 1.552 & 0.401 \\
\hline LM5 & 9.27 & 0.961 & 0.248 & 8.73 & 1.438 & 0.371 \\
\hline
\end{tabular}

Table 7. Independent sample t-test results of the post-course survey

\begin{tabular}{|c|c|c|c|c|c|c|c|}
\hline & \multicolumn{5}{|c|}{ T-test for equality of means } & \multicolumn{2}{|c|}{$95 \%$ Confidence interval of the difference } \\
\hline & $t$ & $\mathrm{df}$ & $p$-value & Mean difference & Std. error difference & Lower & Upper \\
\hline VII & -0.276 & 28.00 & 0.785 & -0.200 & 0.726 & -1.687 & 1.287 \\
\hline VI2 & 2.741 & 28.00 & 0.011 & 1.400 & 0.511 & 0.354 & 2.446 \\
\hline VI3 & -0.178 & 28.00 & 0.860 & -0.133 & 0.747 & -1.664 & 1.398 \\
\hline VI4 & 1.592 & 28.00 & 0.123 & 0.933 & 0.586 & -0.267 & 2.134 \\
\hline VEl & 0.000 & 28.00 & 1.000 & 0.000 & 0.654 & -1.340 & 1.340 \\
\hline$V E 2$ & 0.000 & 28.00 & 1.000 & 0.000 & 0.726 & -1.487 & 1.487 \\
\hline VE3 & -1.358 & 28.00 & 0.185 & -1.000 & 0.736 & -2.508 & 0.508 \\
\hline$V E 4$ & -0.818 & 28.00 & 0.420 & -1.200 & 1.467 & -4.205 & 1.805 \\
\hline VT1 & 0.097 & 28.00 & 0.923 & 0.067 & 0.686 & -1.339 & 1.473 \\
\hline VT2 & 0.794 & 28.00 & 0.434 & 0.667 & 0.840 & -1.054 & 2.387 \\
\hline VT3 & 0.572 & 28.00 & 0.572 & 0.400 & 0.700 & -1.033 & 1.833 \\
\hline VT4 & 0.453 & 28.00 & 0.654 & 0.333 & 0.735 & -1.172 & 1.839 \\
\hline$E B 1$ & 1.862 & 28.00 & 0.073 & 1.067 & 0.573 & -0.107 & 2.240 \\
\hline$E B 2$ & 0.650 & 28.00 & 0.521 & 0.533 & 0.820 & -1.147 & 2.214 \\
\hline$E B 3$ & 0.554 & 28.00 & 0.584 & 0.267 & 0.481 & -0.719 & 1.253 \\
\hline EB4 & 0.433 & 28.00 & 0.669 & 0.400 & 0.924 & -1.494 & 2.294 \\
\hline EEl & 0.000 & 28.00 & 1.000 & 0.000 & 0.613 & -1.255 & 1.255 \\
\hline EE2 & 2.127 & 22.53 & 0.045 & 1.333 & 0.627 & 0.035 & 2.632 \\
\hline EE3 & 2.190 & 28.00 & 0.037 & 1.200 & 0.548 & 0.077 & 2.323 \\
\hline EE4 & 1.642 & 28.00 & 0.112 & 0.867 & 0.528 & -0.215 & 1.948 \\
\hline$A A 1$ & -1.064 & 22.09 & 0.299 & -1.067 & 1.002 & -3.145 & 1.011 \\
\hline$A A 2$ & 1.284 & 28.00 & 0.210 & 0.867 & 0.675 & -0.516 & 2.250 \\
\hline$A A 3$ & 0.181 & 28.00 & 0.857 & 0.200 & 1.102 & -2.058 & 2.458 \\
\hline$A A 4$ & -2.378 & 28.00 & 0.024 & -2.467 & 1.037 & -4.591 & -0.342 \\
\hline$L M 1$ & 0.704 & 28.00 & 0.487 & 0.267 & 0.379 & -0.509 & 1.043 \\
\hline$L M 2$ & 0.188 & 28.00 & 0.852 & 0.133 & 0.710 & -1.320 & 1.587 \\
\hline$L M 3$ & 1.284 & 28.00 & 0.210 & 0.867 & 0.675 & -0.516 & 2.250 \\
\hline LM4 & 0.089 & 28.00 & 0.930 & 0.067 & 0.750 & -1.470 & 1.603 \\
\hline LM5 & 1.194 & 24.43 & 0.244 & 0.533 & 0.447 & -0.387 & 1.454 \\
\hline
\end{tabular}


The survey results indicated that on average, MMU students had a slightly higher means in most of the constructs as compared to Chiba-U students. To justify the validity of these results, the Levene's Test and independent samples t-test were used.

Table 7 illustrates the t-test results of the constructs that pass the Levene's Test. Similar to the pre-course survey results, majority of the constructs show that the 95\% CI for mean difference contains the tested value 0 and the p-value of more than 0.05 , respectively. Hence there is no difference for these constructs in means for each score between MMU and Chiba-U students. However, there are 4 constructs with p-values less than 0.05 , namely the AA4, EE2, EE3 and VI2:

- For AA4, the sample mean for MMU students is $4.27 \pm 2.815$ while the sample mean for Chiba-U students is $6.73 \pm 2.865$. The $95 \%$ CI for mean difference is [-4.591, -0.342], which does not contain 0 . Thus, there is a difference in mean scores between MMU and Chiba-U students, in which the scores of Japanese students are higher than Malaysian Students

- For EE2, the sample mean for MMU students is $8.73 \pm 1.223$ while the sample mean for Chiba-U students is $7.4 \pm 2.098$. The $95 \%$ CI for mean difference is $[0.035,2.632]$, which does not contain 0 . Thus, there is a difference in mean scores between MMU and Chiba-U students, in which the scores of MMU students are higher than Chiba-U students

- For EE3, the sample mean for MMU students is $8.33 \pm 1.291$ while the sample mean for Chiba-U students is $7.13 \pm 1.685$. The $95 \%$ CI for mean difference is $[0.077,2.323]$, which does not contain 0 . Thus, there is a difference in mean scores between MMU and Chiba-U students, in which the scores of MMU students are higher than Chiba-U students

- For VI2, the sample mean for MMU students is $9.2 \pm 0.862$ while the sample mean for Chiba-U students is $7.8 \pm 1.781$. The $95 \%$ CI for mean difference is $[0.354,2.446]$, which does not contain 0 . Thus, there is a difference in mean scores between Malaysian and Japanese students, in which the scores of Malaysian students are higher than Japanese students

\section{Discussion}

This section presents the discussions on the results obtained from all three phases of experiments based on the constructs. After that, overall observations are presented discussing the implications of the finding.

For the Intrinsic Goal Orientation (VI) measurements, it was observed that MMU students, on average, scored higher means in VI compared to Chiba$\mathrm{U}$ students, before and after the program. Both groups of students showed high intrinsic motivation with mean scores for all measurements in this construct between the range of 6.79 to 8.6 and 7.2 to 9.2 for pre-course and post-course, respectively. The pre-course t-test showed that there was no significant difference in means for each VI scores between MMU and Chiba-U students. The post-course t-test, however, showed that VI2 carried a difference in mean scores between MMU and Chiba-U students, with the scores of MMU students higher compared to Chiba-U students. This finding indicated that MMU students were more intrinsically motivated than Chiba-U students in the GSP. These course materials aroused their curiosity and inspired them to learn more despite the difficulty. From the second phase observational measurement during the GSP, it was observed that both MMU and Chiba-U students were equally trying their best to understand the course problems and spent significant amount of time and effort to formulate solutions for these problems. Such observation was also reflected in the postsurvey results where most VI measurements (except for VI2) showed no significant difference in mean scores between the two groups of students.

For the Extrinsic Goal Orientation (VE) measurements, it was observed that MMU students, on average, scored slightly lower means in VE compared to Chiba-U students, before and after the program. However, the pre-course and post-course t-test showed that there was no significant difference in means for each VE scores between MMU and Chiba-U students. Both groups of students showed moderately high extrinsic motivation with mean scores for all measurements in this construct between the range of 6.4 to 7.36 and 6.6 to 8.73 for pre-course and post-course, respectively. Such finding indicated that Chiba- $U$ students were more extrinsically motivated than MMU students, possibly because GSP was a 4 credit subject for Chiba-U students while it was a voluntary subject for MMU students. From the second phase observational measurement during the GSP, it was observed that both MMU and ChibaU students were equally trying their best to achieve good performance in the program. Such observation was also reflected on the post-survey results where all the VE measurements showed no significant differences in mean scores between the two groups of students.

It was observed that the VI and VE measurements of MMU and Chiba-U students, on average, had improved after the GSP course. The average VI and VE scores of MMU students had improved from 7.7975 to 8.0825 and from 6.7525 to 7.7325 , respectively, before and after the GSP. On the other hand, the average VI and VE scores of Chiba-U students improved from 7.305 to 7.5825 and from 7.0875 to 8.2825 , respectively, before and after the GSP. This improvement was supported by the second phase observational measurement during the GSP course, where all students were highly motivated in completing their daily milestones and striving the best they could to perform well. It is interesting to note that the improvement were more significant for extrinsic goal motivation (VE) for both groups of students. 
For the Task Value (VT) measurements, it was observed that MMU students, on average, scored higher means in VT compared to Chiba-U students, before and after the program. The pre-course t-test showed that there were differences in means for VT3 and VT4 scores between MMU and Chiba-U students, where MMU students scored higher in both cases. The post-course ttest, on the other hand, showed no significant differences in means for each VT score between MMU and Chiba-U students. Note that the average VT scores of MMU and Chiba-U students had improved from 7.7 to 7.985 and from 6.535 to 7.615 , respectively, before and after the GSP. The significant increased in Chiba-U students' VT measurement signified the improvement of Chiba-U students' perception on the value of the learning tasks after joining the GSP. The ranges of mean scores for the VT measurements of both groups were between 5.79 to 7.47 and 7.13 to 8.2 for pre-course and post-course, respectively. An obvious increase was again observed in this construct, showing a change from having a moderately high rating for task value to high task rating after joining GSP. Learning tasks in GSP were thus seemed to change students' perception on how importance these tasks were for facilitating successful learning.

For the Control of Learning Belief (EB) measurements, it was observed that MMU students, on average, achieved higher means in EB compared to Chiba-U students, before and after the program. The precourse and post-course t-test showed that there was no significant difference in means for each EB score between MMU and Chiba-U students. The average EB scores of MMU and Chiba-U students had improved from 7.3475 to 8.0325 and from 7.0025 to 7.4675 , respectively, before and after the GSP. Such improvement in EB is supported by the second phase observational measurement during the GSP course, where all students were equally dedicated and willingly putting extra hours and efforts to learn and understand the GSP contents. The ranges of mean scores for the EB measurements of both groups were between 5.89 to 8.13 and 6.87 to 8.67 for pre-course and post-course, respectively. Both groups of students were having at least moderately high to high expectation that their effort during the GSP will and had contributed to the achievement of learning goals.

For the Self-Efficacy for Learning and Performance (EE) measurements, it was observed that MMU students, on average, achieved higher means in EE compared to Chiba-U students, before and after the program. The precourse Mann-Whitney Test showed that there was difference in mean for EE2 scores between MMU and Chiba-U students, with the scores of MMU students higher compared to Chiba-U students. The post-course ttest showed that EE2 and EE3 carried statistical differences in mean scores between MMU and Chiba- $U$ students, with the scores of MMU students again higher compared to Chiba-U students. Such findings reflected that MMU students were more confident in understanding the course contents of the GSP than the Chiba-U students. This may be due to the fact that the language used in delivering the GSP course was English, which was the less preferred medium of communication by most Chiba-U students, possibly due to poorer English proficiency. Nevertheless, the average EE scores of MMU and Chiba-U students had improved from 7.4675 to 8.1325 and from 6.4125 to 7.2825 , respectively, before and after the program. Such improvement in EE was also demonstrated by the students in the second phase observational measurement during the GSP, where half of the students showed outstanding performance in the GSP despite the fact that they claimed that English was a challenge to them. The ranges of mean scores for the EE measurements of both groups were between 6.29 to 8.2 and 7.13 to 8.73 for pre-course and post-course, respectively. This obvious change in range was mainly due to the increase in confident demonstrated by the Chiba-U students. Hence, toward the end of the GSP, the two groups of students shown high confident that they possess the necessary skills to complete the learning tasks.

For the Test Anxiety (AA) measurements, it was observed that MMU students, on average, had lower means in AA compared to Chiba-U students, before and after the program. The pre-course and post-course t-test showed that there was no significant difference in means for each AA score between MMU and Chiba University students. The average AA scores of MMU students had a slight increase from 5.345 to 5.5025 , before and after the GSP. On the other hand, the average AA scores of Chiba University students decreased from 6.5 to 6.1175 , before and after the GSP. This finding was expected considering the fact that MMU students had less pressure taking the GSP course as an extra subject. The ranges of mean scores for the AA measurements of both groups were between 4.2 to 7.64 and 4.27 to 6.73 for pre-course and post-course, respectively. Both groups of students were having moderate to moderately high test anxiety at the beginning of GSP and this changed to moderate level toward the end of the GSP. The change was obviously seen among the Chiba-U students probably due to the positive feedbacks obtained and confident cultivated during the GSP.

For the Self Perception of Learning Motivation (LM) measurements, it was observed that MMU students, on average, scored higher means in LM compared to Chiba$\mathrm{U}$ student, before and after the program. The pre-course t-test showed that there were differences in means for LM2, LM3 and LM5 scores between MMU and Chiba-U students. The post-course t-test, on the other hand, showed no difference in means for each LM scores between MMU and Chiba-U students. The average LM scores of MMU students showed slight improvement from 8.76 to 8.788 , before and after the GSP. On the other hand, the average LM scores of Chiba-U students 
showed significant improvement from 7.4 to 8.412 , before and after the GSP. The significant increase in Chiba-U students' LM measurements signified the Chiba-U students' positive change in self perception of their learning motivation.

By examining the changes of the average scores for each construct before and after the GSP, it was observed that the average scores of all constructs for both MMU and Chiba-U students improved after the GSP course, with the improvement of Chiba-U students higher than the improvement of MMU students. This was supported directly by the results of the students' self-perception of Learning Motivation (LM constructs) as well as indirectly by the results of the individual vignette of value, expectancy and affective components of learning motivation. This finding conclusively shows that students' learning motivation improved after joining the GSP.

Comparing the average VI and VE measurements, it could be observed that MMU students' intrinsic goal orientation was higher than their extrinsic goal orientation in both the measurements before and after the GSP. This finding was not in line with the results found from the previous works (Ainol and Isarji, 2009; Samsiah et al., 2009; Thang et al., 2011) where Malaysian students' extrinsic learning motivation was higher than their intrinsic learning motivation. Such findings, however, can be justified by the fact that GSP was a self-volunteered course for MMU students. The students were well aware of the nature of GSP before signing up the course and there never was an extrinsic learning motivation in the first place when students joined the GSP (i.e. to perform well academically).

Analysis of the Value components (Fig. 1) of the learning motivation showed that all constructs (Intrinsic Goal Orientation VI, Extrinsic Goal Orientation VE and Task Value VT) showed increases in importance in motivating the students' to learn in the GSP. Students were observed to be more cognitively motivated to learn as they embarked more in the learning activities in the GSP based on the results of this study. By referring to Table 8 on the scores comparison of VE, it was observed that the scores had significantly improved at the end of the GSP (an increase of 0.98 for MMU students and 1.195 for Chiba-U students). The significant improvement of VE for Chiba-U students was expected considering the fact that GSP tie to their academic performance. The unexpected part was the significant improvement (the most significant increase) of VE for MMU students as there were no significant external factors (such as grades and rewards) for them to achieve. This may be due to the positive influences of Chiba-U students toward MMU students throughout the GSP. It should also be noted that the increase in VE was the most significant increase motivation construct for Chiba$\mathrm{U}$ students. The high external motivation of Chiba-U students might have indirectly affects the external motivation of MMU students.

This phenomenon can also be observed on the VT scores, where MMU students' high task value motivation might have positively influence the Chiba-U students task value motivation, with significant improvement observed toward the end of the GSP (Table 8 for VT scores). This finding implies that a group of students with low external motivation and low task value motivation can be positively influenced by another group of students with high external and task value motivation by undergoing a program similar to the GSP setup. It was also observed that the effect was two-way, where external motivation and task value motivation of all students (those with initially low motivation and those having initially high motivation) improved after the collaborative learning activities. Such finding might potentially be extended to any learning endeavor seeking to improve learning motivation. Analyzing the expectancy components (Fig. 1) of the learning motivation showed that Self-Efficacy for Learning and Performance (EE) had greater impact over the Control of Learning Belief (EB) in motivating the students to learn especially toward the end of the program, though the difference was minor. Students were observed to be gaining more confident to learn when they were participating more in the learning activities. This was particularly obvious among the Chiba-U students.

Analyzing the affective component (Fig. 1) of the learning motivation showed that Test Anxiety (AA) had only moderate impact on the students' motivation to learn especially toward the end of the program. This was shown to be the lowest motivating factor among all the components of learning motivation. It was also interesting to note that this was the only motivation component showing inverse change before and after the GSP and particularly happening only among the Chiba-U students. They felt less performance anxiety compared to the time before the program as the GSP was completed.

Students' self-perception of own motivation for learning showed significant increase among Chiba-U students (Table 8). MMU students showed only minor improvement in self-perceived learning motivation, before and after the GSP.

Overall, the emotional component played a less significant role in students' motivation for learning. Between the value and expectancy components, value components showed more impact toward motivating the students to learn. Thus, overall, value component seemed to affect the students most when it comes to learning motivation. Students were motivated mostly by their value perception of embarking in the learning endeavor. This was followed closely by the expectancy components and to a lesser extent, the emotional motivation for learning. 
Table 8. Average scores comparisons of constructs before and after the GSP

\begin{tabular}{|c|c|c|c|c|c|c|}
\hline & \multicolumn{3}{|c|}{ MMU's means } & \multicolumn{3}{|c|}{ Chiba University's means } \\
\hline & Before & After & Diff. & Before & After & Diff. \\
\hline$\overline{V I}$ & 7.7975 & 8.0825 & 0.2850 & 7.3050 & 7.5825 & 0.2775 \\
\hline$V E$ & 6.7525 & 7.7325 & 0.9800 & 7.0875 & 8.2825 & 1.1950 \\
\hline$V T$ & 7.7000 & 7.9850 & 0.2850 & 6.5350 & 7.6150 & 1.0800 \\
\hline$E B$ & 7.3475 & 8.0325 & 0.6850 & 7.0025 & 7.4675 & 0.4650 \\
\hline$E E$ & 7.4675 & 8.1325 & 0.6650 & 6.4125 & 7.2825 & 0.8700 \\
\hline$A A$ & 5.3450 & 5.5025 & 0.1575 & 6.5000 & 6.1175 & -0.3830 \\
\hline$L M$ & 8.7600 & 8.7880 & 0.0280 & 7.4000 & 8.4120 & 1.0120 \\
\hline
\end{tabular}

These results imply that for two Asian demographics from distinct cultural backgrounds, exchange programs such as GSP may improve students' learning motivation. In particular, the learning process in this kind of program is motivated mainly by the value aspects followed by the expectancy aspects of motivation. The success of collaborative learning in this setting may well suggest that cross-cultural learning programs are a potential tool for improving students' learning motivation. Thus, future work in this aspect might include enrolling students with low initial learning motivation and test for the change in learning motivation after the program.

\section{Limitations}

Several factors can be thought to have contributed to the limitations of this research. First, scholars have found that cultural tendencies impact on self-evaluation. For example, Heine et al. (2001) argued that Japanese students tend to evaluate their confidence and abilities lower than for instance students who were raised in the United States. This tendency might explain why most of the average scores of pre- and post-course surveys for Chiba-U students are lower than MMU students.

Second, average scores of students' motivations for both universities might be affected by the factor of location. As MMU students were traveling to Japan specifically for the purpose of joining GSP, their general motivation and expectations for this course might have been higher than Chiba-U's.

Third, the fact that MMU students received a scholarship should also be taken into account. All the MMU students received a scholarship of 80,000 yen from JASSO (Japan Students Services Organization) after their arrival in Japan and before the end of the program. Receiving this significant amount of money might have made them feel more motivated and responsible towards GSP.

Fourth, there might be an affinity between the course topic and students' background. Since the course topic was life space and healthcare technology, it might be that MMU students, 12 of whom were engineering majors were more motivated to learn in this course than ChibaU students, only of whom were engineering majors.

Finally, a fifth factor has to do with the nature of the Global Study Program itself. As mentioned in the beginning of this paper, the topic-related issues about which students need to suggest solutions or ideas for improvement are not set in advance by the course conveners, but have to be discovered by the students themselves in the process of their field research. This characteristic, in combination with the collaborative focus of the program and the emphasis on process rather than product, may diminish at the outset extent to which students can perceive external goals which would have motivated them to participate.

\section{Conclusion}

Learning motivation is the key influence in the learning process. This study attempted to determine the change in learning motivation of 15 undergraduate students from Multimedia University, Malaysia after joining an oversea study program, known as the GSP, organized by Chiba University in Japan. Together with another 15 undergraduate students from Chiba University, Japan, the 30 students underwent a series of lectures, workshops, fieldworks and presentations collaboratively in order to provide solutions for existing problems in the Japanese society. The students' learning motivation was being examined in three phases: the precourse survey, the daily observational measurements during course period and the post-course survey.

The results indicated that the learning motivation of Multimedia University undergraduate students had improved after joining the GSP. Such improvements may be due to the following reasons: 1. Multimedia University students were having less stress and were exam-free in this program. Hence they could fully concentrate themselves on the course contents without pressure. 2. The collaborations with Chiba University students had created a context for collaborative learning, which improved the motivations of both parties. The study indicated that the learning motivation of Chiba University undergraduate students had significantly improved at the end of the GSP. The study also revealed that a group of students with low learning motivation can be influenced by a group of highly motivated students by undergoing program with setup similar to the GSP and the improvements are two-way (i.e., to all students). 


\section{Future Plans}

It is planned to continue the GSP between Multimedia University and Chiba University on yearly basis. More samples of data can be collected and analyzed from the future GSP. Other than GSP, it is also possible to extent the collaboration between both universities, such as student exchange, staff exchange and postgraduate exchange.

\section{Acknowledgement}

The authors would like to express the upmost gratitude to all supports provided by the research centres in Chiba University and the social communities in Chiba, Japan.

\section{Author's Contributions}

Lim Way Soong: Participated in experiment and result analysis, involved in the sample data collection and GSP course delivering.

Leow Meng Chew: Involved in the organized of study, contributed to the drafting of article and involved in critical reviewed of manuscript.

Lim Chot Hun: Designed of research plan and organized the study, sample data collection and analysis, writing of the manuscript.

Hiroki Igarashi; Ioannis Gaitanidis and Satoko Shao-Kobayashi: GSP course planning and delivering, participated in experiment result analysis and contributed to critical reviewed of manuscript.

Note: The order of Authors from College of Liberal Arts and Sciences, Chiba University, Chiba Japan is alphabetically-arranged.

\section{Ethics}

This article is original and contains unpublished materials. The corresponding author confirms that all of the other authors have read and approved the manuscript and no ethical issues involved.

\section{References}

Ainol, M.Z. and H.S. Isarji, 2009. Motivation to learn a foreign language in Malaysia. GEMA Online $\mathrm{J}$. Language Stud., 9: 73-87.

Bargh, J.A., P.M. Gollwitzer, A. Lee-Chai, K. Barndollar and R. Trotschel, 2001. The automated will: Nonconscious activation and pursuit of behavioral goals. J. Personality Social Psychol., 81: 1014-1027.

Habibah, E., A. Rahman and W. Rafaei, 1995. Achievement motivation of University students. Pertanika J. Soc. Sci. Hum., 3: 1-10.
Heine, S.J., S. Kitayama and D.H. Lehman, 2001. Cultural differences in self-evaluation: Japanese readily accept negative self-relevant information. J. Cross-cultural Psychol., 32: 434-443.

Kleinginna, P., Jr. and A. Kleinginna, 1981. A categorized list of motivation definitions, with suggestions for a consensual definition. Motivation Emotion, 5: 345-379.

Koo, Y.L., 2003. Asian pacific perspectives: Challenges and issues in multicultural lingual contexts. $3 \mathrm{~L} \mathrm{~J}$. Language Teaching, Linguistics Literature, 8: 1-7.

Maferima, T.T. and F. Ayelet, 2014. How to measure motivation: A guide for the experimental social psychologist. Soc. Personality Psychol. Compass, 8: 328-341. DOI: $10.1111 / \mathrm{spc} 3.12110$

Ohata, K., 2005. Potential sources of anxiety for Japanese learners of English: Preliminary case interviews with five Japanese College Students in the U.S. TESL-EJ, 9: 2-23.

Othman, T., S.L. Wong, C.A. Shah and A. Nabilah, 2009. Uncovering Malaysian students' motivation to learning science. European J. Social Sci., 8: 266-276.

Pintrich, P.R., D.A. Smith, T. Gracia and W.J. McKeachie, 1991. A Manual for the use of the Motivational Strategies for Learning Questionnaire (MSLQ). University of Michigan: National Centre for Research to Improve Postsecondary Teaching and Learning.

Rachel, M.C. and M.M. Holly, 2013. Developing an instrument to measure motivation, learning strategies and conceptual change. Proceedings of the 120th ASEE Annual Conference and Exposition, (AAE' 13), Atlanta, Georgia.

Ryan, R.M., K.M. Sheldon, T. Kasser and E.L. Deci, 1996. All Goals are not Created Equal: An organismic perspective on the nature of goals and their regulation. In: The Psychology of Action: Linking Cognition and Motivation to Behavior, Gollwitzer, P.M. and J.A. Bargh (Eds.), Guilford Press, New York, pp: 7-26.

Salmiza, S., 2014. Malaysian students' motivation towards physics learning. Eur. J. Sci. Math. Educ., 2: $223-232$.

Samsiah, B., J. Kamaruzaman, A.A. Nurazila, M.S. Musdiana and T. Taniza, 2009. Motivation and attitude in learning English among UiTM students in the northern region of Malaysia. English Language Teaching, 2: 16-20.

Schmuck, P., T. Kasser and R.M. Ryan, 2000. Intrinsic and extrinsic goals: Their structure and relationship to well-being in German and U.S. college students. Soc. Indicators Res., 50: 225-241. DOI: 10.1023/A:1007084005278

Siddhu, G.K., 2009. Empowering Learners through Strategy Training. In: Learner Autonomy: Research and Practice in Malaysia and Singapore, Thang, S.M. and B. Sinclair (Eds.), Petaling Jaya, Pearson Malaysia, pp: 106-134. 
Thang, S.M., 2009. Investigating autonomy of Malaysian ESL learners: Comparison between public and private universities. 3L Language, Linguistics Literature South East J. English Language Stud., 17: 97-124.
Thang, S.M., S.L. Ting and M.J. Nurjanah, 2011. Attitudes and motivation of malaysian secondary students towards learning English as a second language: A case study. 3L Southeast Asian J. English Language Stud., 17: 40-54. 